University of Nebraska - Lincoln

DigitalCommons@University of Nebraska - Lincoln

Faculty Publications from the Department of Electrical \& Computer Engineering, Department Electrical and Computer Engineering

$5-1-2001$

\title{
Infrared optical properties of aged porous GaAs
}

\author{
S. Zangooie \\ University of Nebraska-Lincoln \\ Mathias Schubert \\ University of Nebraska-Lincoln, mschubert4@unl.edu \\ T. E. Tiwald \\ J.A. Woollam Co. \\ John A. Woollam \\ University of Nebraska-Lincoln, jwoollam1@unl.edu
}

Follow this and additional works at: https://digitalcommons.unl.edu/electricalengineeringfacpub

Part of the Electrical and Computer Engineering Commons

Zangooie, S.; Schubert, Mathias; Tiwald, T. E.; and Woollam, John A., "Infrared optical properties of aged porous GaAs" (2001). Faculty Publications from the Department of Electrical and Computer Engineering. 42.

https://digitalcommons.unl.edu/electricalengineeringfacpub/42

This Article is brought to you for free and open access by the Electrical \& Computer Engineering, Department of at DigitalCommons@University of Nebraska - Lincoln. It has been accepted for inclusion in Faculty Publications from the Department of Electrical and Computer Engineering by an authorized administrator of DigitalCommons@University of Nebraska - Lincoln. 


\title{
Infrared optical properties of aged porous GaAs
}

\author{
S. Zangooie and M. Schubert \\ Center for Microelectronic and Optical Materials Research, and Department of Electrical \\ Engineering, University of Nebraska, Lincoln, Nebraska 68588 \\ T.E. Tiwald \\ J.A. Woollam Co., Inc., 645 M Street, Suite 102, Lincoln, Nebraska 68508 \\ J.A. Woollam ${ }^{\text {a) }}$ \\ Center for Microelectronic and Optical Materials Research, and Department of Electrical \\ Engineering, University of Nebraska, Lincoln, Nebraska 68588
}

(Received 20 September 2000; accepted 23 February 2001)

\begin{abstract}
Aging properties of porous GaAs were investigated nondestructively using variable angle of incidence infrared spectroscopic ellipsometry. In addition to the thickness and volume porosity, properties of the solid part of the porous material are investigated in terms of the long-wavelength dielectric function and chemical composition. The high sensitivity is employed to detect and identify infrared resonant absorptions related to different vibration modes of cubic and amorphous $\mathrm{As}_{2} \mathrm{O}_{3}$. Resonances centered at $333.3,480,785.8,838$, and $1045.5 \mathrm{~cm}^{-1}$ are from cubic $\mathrm{As}_{2} \mathrm{O}_{3}$, whereas resonances centered at 350, 490, and $808.5 \mathrm{~cm}^{-1}$ are from amorphous $\mathrm{As}_{2} \mathrm{O}_{3}$.
\end{abstract}

Recent widespread interest in luminescence properties of porous silicon, ${ }^{1,2}$ has led to efforts to investigate properties of other semiconductor-based porous materials such as porous $\mathrm{SiC}$ and $\mathrm{GaAs}^{3-7}$ The prospects of adoption of electronic, thermal, and optical properties of the bulk semiconductors by the corresponding high surface area porous structures, provides application possibilities in optics, sensor technology, and electronics. The advantageous electronic properties of GaAs compared to silicon have led to its use in high-speed diodes and field effect transistors and circuits. Furthermore, anodization of GaAs results in formation of porous layers that luminesce in the visible, at higher photon energies than porous silicon. ${ }^{8,9}$ Hence, development of nondestructive tools for optical and microstructural characterization of porous GaAs and its aging is of importance. Variable angle of incidence infrared spectroscopic ellipsometry (IRSE), being intrinsically sensitive to the presence of thin films, has advantages compared with the more traditional reflectance spectroscopy. For example and imaginary parts of the dielectric function of the material can be determined simultaneously without need for additional measurements on a reference sample or employment of the Kramers-Kronig relation requiring extrapolation of experimental data beyond the measurement range. IRSE has been shown to be effective for characterization of porous silicon and porous $\mathrm{SiC}^{3,10} \mathrm{In}$ this work, infrared optical properties of freshly prepared and aged porous GaAs formed in highly degenerate

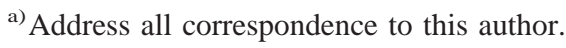

p-type GaAs are investigated. Optical properties of bulk material are compared with the solid phase of the porous material.

Porous GaAs samples were prepared using $p$-type, Zndoped, wafers with (100) crystal orientation. Highly degenerate wafers were used to obtain uniform porous layers. ${ }^{5}$ Wafers were obtained from Materials Technology International (MTI) Corporation. Electrochemical etching was performed in a mixture of $\mathrm{HCl}$, water, and ethanol (volume ratio 2:2:6). A Teflon coated magnet stirred the etch solution to maintain uniform distribution of $\mathrm{HCl}$. Current densities were in the range $30-50 \mathrm{~mA} / \mathrm{cm}^{2}$. Etching times were in the range of 15-120 s. Current density and etching time used for the representative sample discussed here were $30 \mathrm{~mA} / \mathrm{cm}^{2}$ and $120 \mathrm{~s}$, respectively. Prior to etching, samples were suspended vertically in the etch solution for $3 \mathrm{~min}$ to remove the native oxide. The counter-electrode was a platinum plate positioned about $5 \mathrm{~cm}$ from the $\mathrm{GaAs}$ sample. After anodization, samples were placed in ethanol for $10 \mathrm{~min}$ and finally blown dry in nitrogen. Ellipsometry measurements at room temperature in the $250-2000 \mathrm{~cm} \mathrm{~cm}^{-1}$ range, with $2 \mathrm{~cm} \mathrm{~cm}^{-1}$ resolution, were carried out using a commercially available variable angle IRSE, using three angles of incidence of $50^{\circ}, 60^{\circ}$, and $70^{\circ}$. Aging properties of samples were investigated by measurements on the same spot on the samples, with 10-day intervals.

The measured quantity in ellipsometry ${ }^{11}$ is the complex reflectance ratio, is expressed as

$$
\rho=\frac{R_{p}}{R_{s}}=\tan (\psi) \exp (i \Delta) .
$$


$R_{p}$ and $R_{s}$ are the complex reflection coefficients for $p$ - and $s$-polarized light, respectively. The amplitude ratio $\tan (\psi)$ and the relative phase changes $\Delta$ for $p$ - and $s$-light components upon reflection off the sample are the measured ellipsometry parameters. From experimentally determined $\rho$, information can be obtained about the optical and microstructural properties of the material under study in terms of the complex dielectric function $\epsilon=\epsilon_{1}+i \epsilon_{2}$, thickness, and porosity.

Infrared optical properties of GaAs are influenced significantly by the free carrier concentration. ${ }^{12}$ Optical characteristics of $p$-type GaAs are complicated by penetration of the Fermi level into nondegenerate valence bands, providing contributions from heavy holes as well as light holes. ${ }^{13-15}$ Hence, partial filling and nondegeneracy of the valence bands require consideration of both carrier types. Optical properties of the $p$-type GaAs substrates and the solid phase in terms of the dielectric function is modeled using the following expression: ${ }^{15,16}$

$$
\begin{aligned}
\epsilon(\omega)= & \epsilon_{\infty}+\frac{\epsilon_{\infty}\left(\omega_{\mathrm{LOB}}^{2}-\omega_{\mathrm{TOB}}^{2}\right)}{\omega_{\mathrm{TOB}}^{2}-\omega^{2}-i \omega \gamma_{\mathrm{B}}} \\
& -\frac{\epsilon_{\infty} \omega_{\mathrm{phh}}^{2}-\frac{\epsilon_{\infty} \omega_{\mathrm{plh}}^{2}}{\omega\left(\omega+i \Gamma_{\mathrm{lh}}\right)}}{\left.\omega+i \Gamma_{\mathrm{hh}}\right)} \\
& +\sum_{j=1}^{n} \frac{\epsilon_{\infty}\left(\omega_{\mathrm{LO} j}^{2}-\omega_{\mathrm{TO} j}^{2}\right)}{\omega_{\mathrm{TO} j}^{2}-\omega^{2}-i \omega \gamma_{j}}
\end{aligned}
$$

where $\varepsilon_{\infty}$ is the high-frequency dielectric function limit. The second term in Eq. (2) represents the lattice contribution of bulk crystalline GaAs, where $\gamma_{\mathrm{B}}, \omega_{\mathrm{TOB}}$, and $\omega_{\text {LOB }}$ are the phonon damping and infrared (IR)-active transverse-optical (TO) and longitudinal-optical (LO) phonon frequencies, respectively. The third and fourth terms in Eq. (2) are the Drude expressions, which are introduced to take into consideration effects of the multicomponent free carrier plasma, i.e., heavy holes (hh) and light holes (lh) in the highly degenerate semiconductor. Note that the screened plasmon frequencies $\left(\omega_{\text {plh,hh }}\right)$ and the plasmon broadening parameters $\left(\Gamma_{\mathrm{lh}, \mathrm{hh}}\right)$ are related to the carrier concentrations and carrier mobilities. ${ }^{15}$ The last term in Eq. (2) is a series of oscillators, which are similar to the second term of the equation, and are used here for modeling the IR resonance absorptions related to chemical signatures associated with aged porous GaAs. Note that the depleted surface layer caused by Fermi level pinning to mid-band-gap surface states is not considered in the analysis of bulk GaAs due to negligible changes of the polarization state of the reflected light by the very thin depletion layer in the highly doped samples studied here. ${ }^{14,15,17}$ The Bruggeman effective medium approximation ${ }^{18}$ (EMA) is used to calculate the effective dielectric function $\epsilon_{\text {eff }}$ of the solid phase as well as thickness and porosity of the porous layers.
Characterization of the freshly prepared sample is realized using a two-constituent EMA layer, where the dielectric function of the solid phase is initially chosen to be identical with the dielectric function of crystalline GaAs. Hence, the optical model can be schematically represented as GaAs substrate//EMA (solid phase + void)//ambient. The Drude terms of Eq. (2) did not contribute to the fit, indicating that the solid phase of porous material is depleted of carriers. Thus, parameter values corresponding to the first and second terms of Eq. (2) are used during the first step of the analysis. Agreement between the model generated and experimental data, assuming the solid phase is carrier depleted crystalline $\mathrm{GaAs}$, is shown in Fig. 1. For clarity the result is shown only for one angle of incidence and in the spectral range $250-500 \mathrm{~cm}^{-1}$. Note that the misfit below approximately $300 \mathrm{~cm}^{-1}$ is related to the difference between optical properties of the solid phase and crystalline GaAs. The minimum in the model generated data, situated below the LO phonon frequency of crystalline GaAs at $291.5 \mathrm{~cm}^{-1}$, is related to the Berreman effect described elsewhere. ${ }^{19,20}$ However, the measured Berreman signature is red-shifted by $12.2 \mathrm{~cm}^{-1}$ as compared with the position predicted by the initial model. It must be mentioned that we have also observed a similar red-shift of the LO phonon frequency using Raman spectroscopy. The red-shift is therefore taken into consideration in the analysis of porous GaAs IRSE data. In other words, the solid phase is represented using $\epsilon^{\infty}=10.52$, $\omega_{\text {ТОв }}=267.4 \mathrm{~cm}^{-1}, \omega_{\text {LOB }}=279.3 \mathrm{~cm}^{-1}$ and $\gamma_{\mathrm{B}}=$ $3.1 \mathrm{~cm}^{-1}$. Parameter values, except for the value of $\omega_{\mathrm{LOB}}$, are taken from Ref. 15. The magnitude of the TO-LO splitting is a measure of the polar strength. The lower splitting compared with crystalline GaAs indicating

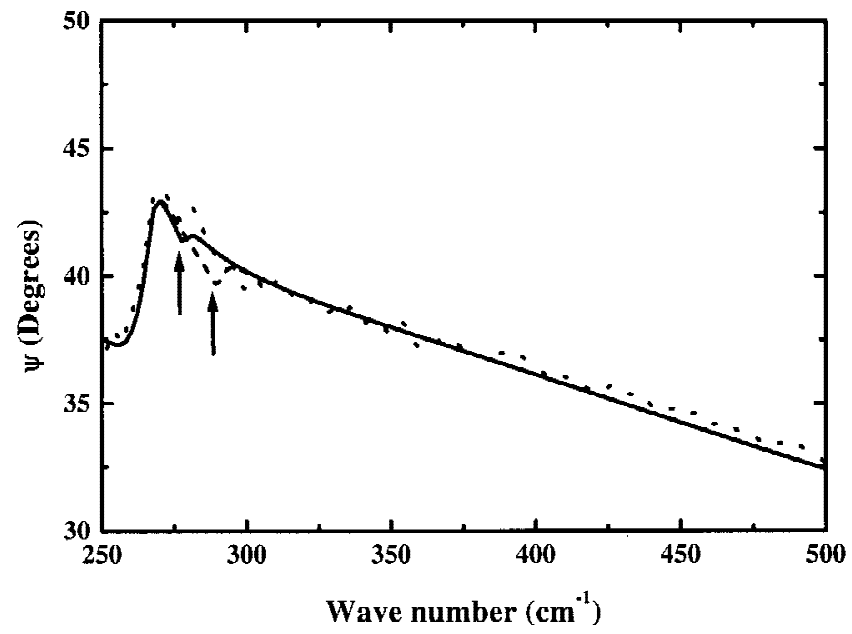

FIG. 1. Model generated (-) and experimental (...) $\psi$ spectra at angle of incidence of $50^{\circ}$ and in the spectral range $250-500 \mathrm{~cm}^{-1}$. The data generated (-----) using a model assuming carrier depleted crystalline GaAs as the solid phase are also shown. The Berreman signatures are marked in the figure. 
lower density of bonds per volume in the solid phase. This phenomenon is related to deviations from perfect crystallinity of the solid phase due to its amorphization and/or salt formation caused by the anodization process. ${ }^{5-7}$ Using the mentioned parameter values, the best fit parameter values for thickness and porosity of the porous GaAs sample were found to be $179.9 \mathrm{~nm}$ and $70.4 \%$, respectively. The agreement between data generated using the final model and experimental data is shown in Figs. 1 and 2.

In Fig. 2 optical response of the as-prepared porous GaAs sample is compared with its response after one month. Note the appearance of several infrared active vibration modes in the aged sample. Optical properties of the aged sample did not change significantly after one month and reached a stable state. The optical model for characterization of the aged sample can be represented as GaAs substrate//EMA (solid phase + void)//ambient, where the first and the last terms of Eq. (2) determine the dielectric function of the solid phase. Four major vibration modes (labeled in Figs. 2 and 3) are identified and modeled along with the thickness and porosity of the aged porous GaAs sample. The final parameter values and the corresponding confidence intervals are shown in Table I. Although, the number of variables in the model is large, parameter correlation problems are avoided because the observed bands are spectrally local, and from the low confidence limits. In the next step the previously determined parameters are kept constant and the model is assumed to provide an accurate baseline for fine structure analyses of the first and second bands. The bands consist of two closely located resonances denoted as $1 \mathrm{~A}, 1 \mathrm{~B}$, $2 \mathrm{~A}$, and $2 \mathrm{~B}$. The $\omega_{\mathrm{TO}}\left(\omega_{\mathrm{LO}}\right.$ and $\gamma$, given in the parentheses) values for the $1 \mathrm{~A}, 1 \mathrm{~B}, 2 \mathrm{~A}$, and $2 \mathrm{~B}$ resonances are found to be $333.3 \mathrm{~cm}^{-1}\left(348 \mathrm{~cm}^{-1}, 11.8 \mathrm{~cm}^{-1}\right), 350 \mathrm{~cm}^{-1}$ $\left(371.2 \mathrm{~cm}^{-1}, 6.5 \mathrm{~cm}^{-1}\right), 480 \mathrm{~cm}^{-1}\left(482 \mathrm{~cm}^{-1}, 6.5 \mathrm{~cm}^{-1}\right)$ and $490 \mathrm{~cm}^{-1}\left(493 \mathrm{~cm}^{-1}, 8.2 \mathrm{~cm}^{-1}\right)$, respectively.

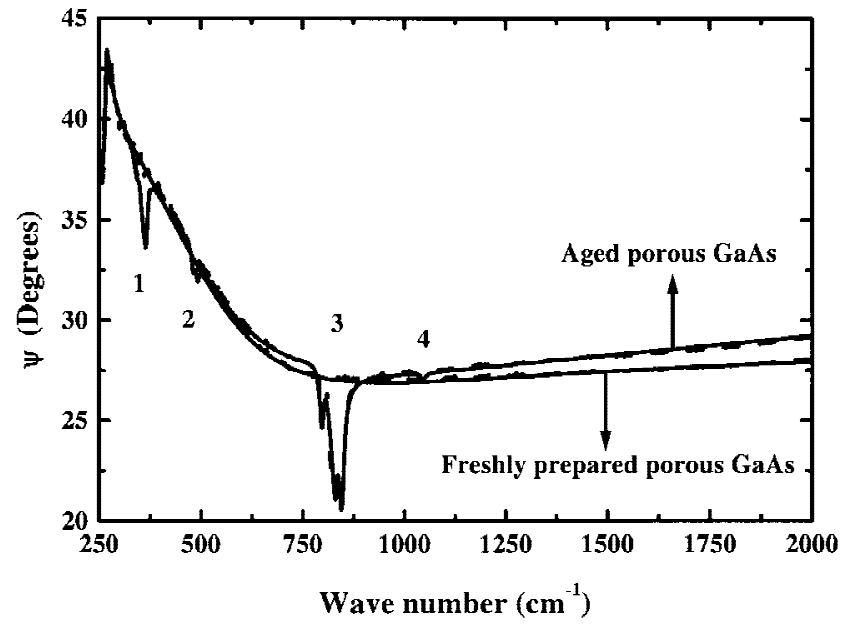

FIG. 2. Model generated (-) and measured (-----) $\psi$ spectra of freshly prepared and aged porous $\mathrm{GaAs}$ at $50^{\circ}$ angle of incidence.
Finally, a relatively weak band at $1045.5 \mathrm{~cm}^{-1}(1046.4$ $\mathrm{cm}^{-1}, 15.4 \mathrm{~cm}^{-1}$ ) is characterized. Agreement between the measured and model generated ellipsometry data of the aged sample is illustrated in Fig. 2. The real part of the dielectric function of the solid phase of the aged sample is shown in Fig. 3 and 4. Using crystalline GaAs as a third constituent in the optical model provided evidence for total oxidation of the solid phase of the freshly prepared sample after about one month. It indicates the crystallites size is less than twice the thickness of native oxide layers $(\sim 20 \AA)$ encountered on surfaces of bulk GaAs. The thickness and porosity of the aged sample are considerably increased compared with the freshly prepared sample. This increase is related to volume expansion of the material caused by oxidation.

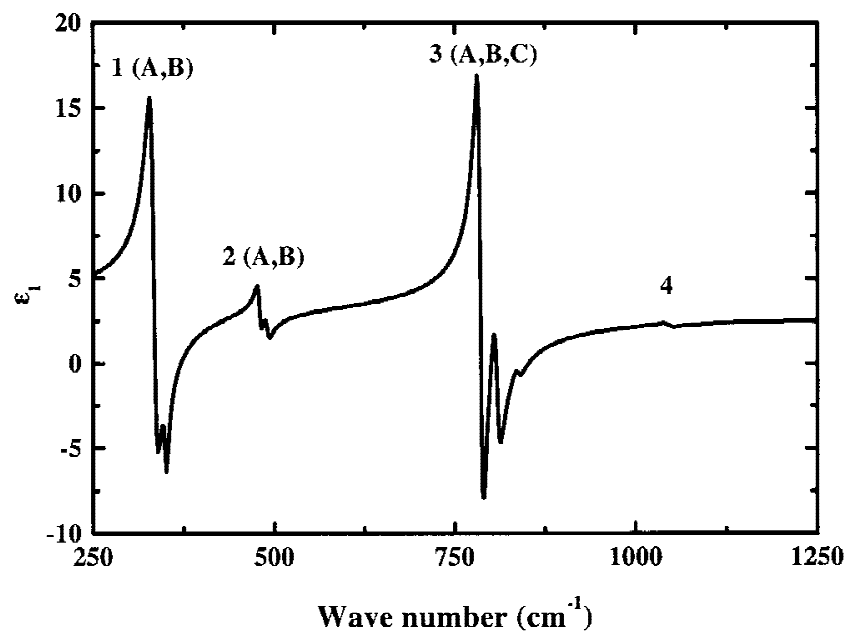

FIG. 3. Real part of the dielectric function of the solid phase of the aged porous GaAs sample in the spectral range $250-1250 \mathrm{~cm} \mathrm{~cm}^{-1}$.

TABLE I. Best fit parameters including 90\% confidence intervals obtained using the first and fifth terms of Eq. (2). $\epsilon_{\infty}=2.9$ is used in the analysis of the solid phase of the aged porous GaAs sample. Thickness and porosity of the aged sample were $539 \pm 4 \mathrm{~nm}$ and $82.8 \pm$ $0.1 \%$, respectively. The resonance numbers are given in the parentheses.

\begin{tabular}{|c|c|}
\hline Model parameters $\left(\mathrm{cm}^{-1}\right)$ & Parameter values $\left(\mathrm{cm}^{-1}\right)$ \\
\hline$\omega_{\mathrm{TO}}(1)$ & $338 \pm 1$ \\
\hline$\omega_{\mathrm{LO}}(1)$ & $371.3 \pm 0.5$ \\
\hline$\gamma \quad(1)$ & $6.2 \pm 0.9$ \\
\hline$\omega_{\mathrm{TO}}(2)$ & $484 \pm 1$ \\
\hline$\omega_{\mathrm{LO}}(2)$ & $489 \pm 1$ \\
\hline$\gamma \quad$ (2) & $11.9 \pm 0.3$ \\
\hline$\omega_{\mathrm{TO}}(3 \mathrm{~A})$ & $785.8 \pm 0.4$ \\
\hline$\omega_{\mathrm{LO}}(3 \mathrm{~A})$ & $799.7 \pm 0.3$ \\
\hline$\gamma \quad(3 \mathrm{~A})$ & $8.4 \pm 0.7$ \\
\hline$\omega_{\mathrm{TO}}(3 \mathrm{~B})$ & $808.5 \pm 0.5$ \\
\hline$\omega_{\mathrm{LO}}(3 \mathrm{~B})$ & $833.8 \pm 0.3$ \\
\hline$\gamma \quad(3 \mathrm{~B})$ & $10.4 \pm 0.4$ \\
\hline$\omega_{\mathrm{TO}}(3 \mathrm{C})$ & $838.0 \pm 0.3$ \\
\hline$\omega_{\mathrm{LO}}(3 \mathrm{C})$ & $853.7 \pm 0.1$ \\
\hline$\gamma \quad(3 \mathrm{C})$ & $11.4 \pm 0.3$ \\
\hline
\end{tabular}


The dielectric function of the solid phase of the aged sample (Fig. 3) shows striking similarities with the dielectric function of arsenloite (cubic $\mathrm{As}_{2} \mathrm{O}_{3}$ ), where the center frequencies of the major resonances are reported to be $340.2,480.5,799.7,836.2$, and $1050 \mathrm{~cm}^{-1}$. ${ }^{21}$ Our results show a splitting of the three first resonances in two distinct bands. Center frequencies associated with amorphous $\mathrm{As}_{2} \mathrm{O}_{3}$ are 354, 520, 625, 810, and 1100 $\mathrm{cm}^{-1}{ }^{21}$ It is likely that the $1 \mathrm{~B}, 2 \mathrm{~B}$, and $3 \mathrm{~B}$ bands are related to amorphous $\mathrm{As}_{2} \mathrm{O}_{3}$. It should be noted that four relatively weaker bands centered at about $305,550,610$, and $1105 \mathrm{~cm}^{-1}$ could also be observed in the spectrum of the sample after ten days. The first two bands were most probably related to amorphous $\mathrm{Ga}_{2} \mathrm{O}_{3}{ }^{21}$ These bands became weaker and broadened with time and were therefore not included in analyses of the one-month-old sample. The changes seem to agree with the previously reported crystallization of amorphous $\mathrm{As}_{2} \mathrm{O}_{3}$ where the bands at about 625 and $810 \mathrm{~cm}^{-1}$ disappear and grow, respectively, after a sufficiently long storage time..$^{21,22}$ It is likely that the solid phase of the aged sample contains amorphous and crystalline $\mathrm{As}_{2} \mathrm{O}_{3}$ as well as amorphous $\mathrm{Ga}_{2} \mathrm{O}_{3}$. However, other species such as $\mathrm{GaAsO}_{3}$ and $\mathrm{GaAsO}_{4}$ may be present. ${ }^{23}$ Note that differences in compositional and morphological nature of the solid phase compared with bulk $\mathrm{As}_{2} \mathrm{O}_{3}$ may explain the observed shifts in center frequencies. For further information concerning different vibration modes of different phases of $\mathrm{As}_{2} \mathrm{O}_{3}$ refer to Refs. 24 and 25. $\epsilon \infty=2.9$ is used in analysis of the solid phase, which is between the values 2.8 and 3.08 used by Palik et al. ${ }^{21}$ for characterization of arsenloite. As also discussed in Ref. 21, using $\epsilon_{\infty}=2.8$ and $\epsilon_{\infty}=3.08$ does not change the parameters in Table I by more than one percent. For example, $\epsilon=$ 2.8 results in thickness and porosity values $0.03 \%$ and $0.75 \%$ lower than the parameter values presented in the table. Furthermore, a least square fit of $\epsilon_{\infty}$ does not improve the fit appreciably. As a consequence, this parameter was kept fixed during the entire analysis. $\epsilon \infty=2.9$ is the value Palik et al. ${ }^{21}$ have used to characterize amorphous $\mathrm{As}_{2} \mathrm{O}_{3}$.

In conclusion, optical properties of solid phase of the freshly prepared sample deviated from crystalline GaAs in a lower TO-LO splitting. The phenomenon attributed to partial amorphization of the solid phase. A total oxidation of the solid phase resulted in considerable volume and thickness expansion. The oxidized solid phase contained arsenolite, amorphous $\mathrm{As}_{2} \mathrm{O}_{3}$ and amorphous $\mathrm{Ga}_{2} \mathrm{O}_{3}$. Resonances centered at 333.3, 480, 785.8, 838, and $1045.5 \mathrm{~cm}^{-1}$ were associated with arsenolite. Resonances at 350,490 , and $808.5 \mathrm{~cm}^{-1}$ originated from amorphous $\mathrm{As}_{2} \mathrm{O}_{3}$.

\section{ACKNOWLEDGMENTS}

Financial support was provided by the Swedish Foundation for International Cooperation in Research and Higher Education, the Center for Microelectronic and Optical Materials Research at Nebraska, and the National Science Foundation, contract DMI-9901510.

\section{REFERENCES}

1. L.T. Canham, Appl. Phys. Lett. 57, 1046 (1990).

2. A. Halimaoui, C. Oules, G. Bomchil, A. Bsiesy, F. Gaspard, R. Herino, M. Ligeon, and F. Muller, Appl. Phys. Lett. 59, 304 (1990).

3. S. Zangooie, P.O.A. Persson, J.N. Hilfiker, L. Hultman, and H. Arwin, J. Appl. Phys. 87, 8497 (2000).

4. S. Zangooie, J.A. Woollam and H. Arwin, J. Mater. Res. 15, 1860 (2000).

5. G. Oskam, A. Natarajan, P.C. Searson, and F.M. Ross, Appl. Surf. Sci. 119, 160 (1997).

6. P. Schmuki, J. Fraser, C.M. Vitus, M.J. Graham, and H.S. Isaacs, J. Electrochem. Soc. 143, 3316 (1996).

7. S. Zangooie and J.A. Woollam, J. Mater. Sci. Lett. (in press).

8. P. Schmuki, D.J. Lockwood, H.J. Labbé, and J.W. Fraser, Appl. Phys. Lett. 69, 1620 (1996).

9. M. Rojas-López, M.A. Vidal, H. Navarro-Contreras, J.M. GraciaJiménez, E. Gómez, and R. Silva-González, J. Appl. Phys. 87, 1270 (2000).

10. S. Zangooie, M. Schubert, C. Trimble, D.W. Thompson, and J.A. Woollam, Appl. Opt. (in press).

11. R.M.A. Azzam and N.M. Bashara, Ellipsometry and Polarized Light (North-Holland, Amsterdam, The Netherlands, 1976).

12. H. Nakano, T. Sakamoto, and K. Taniguchi, J. Appl. Phys. 83, 1384 (1998)

13. S Adachi, GaAs and Related Materials: Bulk Semiconducting and Superlattice Properties (World Scientific Publishing Co., 1994).

14. G. Irmer, M. Wenzel, and J. Monecke, Phys. Rev. B 56, 9524 (1997).

15. S. Zangooie, M. Schubert, D.W. Thompson, and J.A. Woollam (unpublished).

16. P.Y. Yu and M. Cardona, Fundamentals of Semiconductors: Physics and Materials Properties (Springer-Verlag, Berlin, Germany, 1996), Chap. 6.

17. J. Humliček, R. Henn, and M. Cardona, Appl. Phys. Lett. 69, 2581 (1996).

18. D.E. Aspnes, Thin Solid Films 89, 249 (1982).

19. D.W. Berreman, Phys. Rev. 130, 2193 (1963).

20. St. Zollner, J.P. Carrejo, T.E. Tiwald, and J.A. Woollam, Phys. Status Solidi 208, R3 (1998).

21. E.D. Palik, N. Ginsburg, R.T. Holm, and J.W. Gibson, J. Vac. Sci. Technol. 15, 1488 (1978).

22. A. Vaüko, D. Lezal, and I. Srb, J. Non-Cryst. Solids 4, 311 (1970).

23. D.A. Allwood, R.T. Carline, N.J. Mason, C. Pickering, B.K. Tanner, and P.J. Walker, Thin Solid Films 364, 33 (2000).

24. G.N. Papatheodorou and S.A. Solin, Phys. Rev. B 13, 1741 (1976).

25. E.J. Flynn, S.A. Solin, and G.N. Papatheodorou, Phys. Rev. B 13, $1752(1976)$ 